\title{
Analysis of pore type and micro pore structure of reservoir in fault basin--Taking Wuerxun depression as an example
}

\author{
ZHOU Yue ${ }^{l}$, WU Hai-bo \\ ${ }^{1}$ Exploration and Development Research Institute of Daqing Oil Field Co. Ltd, Daqing City, Heilongiiang Province, 163712,China
}

\begin{abstract}
Wuerxun depression is the two main oil-bearing depressions in Hailaer basin. Nantun Formation of Wuerxun depression is the most important oil-gas exploration layer, and reservoir characteristics are the main factors controlling oil-gas enrichment. In this paper, the mineral composition and pore type of Nantun Formation reservoir are analyzed by XRD and SEM. It is clear that the main rock types are lithic sandstone and feldspar lithic sandstone. As a whole, it is compact, with poor connectivity of pores and coexistence of primary and secondary pores. Primary pore is mainly residual primary intergranular pore, and secondary pore is the main reservoir space of Nantun Formation, which lays a foundation for further oil and gas exploration. The rock types of the target layer in the study area are mainly lithic sandstone and feldspathic lithic sandstone. Among them, Tongbomiao formation in Wuerxun depression is dominated by conglomerate, while sandstone in Nantun Formation is mainly lithic arkose and feldspathic lithic sandstone; sandstone in Tongbomiao formation and Nantun Formation in Beier depression is dominated by lithic sandstone and feldspathic lithic sandstone. The rocks of Nantun Formation are compact as a whole, with poor connectivity of pores and coexistence of primary and secondary pores. The primary pores are mainly residual primary intergranular pores, mainly of three types. Secondary pore is the main reservoir space of Nantun Formation, including dissolution intergranular pore, dissolution intergranular pore, interstitial matter dissolution pore, intergranular micro pore and micro fracture of authigenic minerals, among which intergranular dissolution pore is the most developed and super large dissolution intergranular pore is the main one.
\end{abstract}

\section{Preface}

After years of exploration, most of the traps with large scale, shallow burial and simple structure have been drilled; the traps with good shape, large area and good reservoir forming conditions are more and more difficult to find. The exploration degree of complex fault block oil and gas reservoir has entered the stage of fine exploration. The exploration object has changed from structural reservoir to lithologic and lithologic composite reservoir. The exploration object is more complex, the reservoir is buried deeper, the reservoir is thinner, and the scale is smaller. The existing theory and technology can not meet the current demand of fine exploration. It is urgent to carry out fine geological recognition research and realize the transformation from resources to reserves.

\section{Overview of the study area}

Wuerxun depression is the two main oil-bearing depressions in Hailaer basin, which is distributed in NE direction as a whole, and adjacent to the sagangbalansabalage uplift in the West, and the eastern part is connected with Bayan mountain belbuenor uplift, area is
$5340 \mathrm{~km}^{2}$. The main target layer in the study area is Nantun Formation of Lower Cretaceous.

\section{Mineral composition of reservoir}

The rock types of the target layer in the study area are mainly lithic sandstone and feldspathic lithic sandstone. Among them, Tongbomiao formation is mainly composed of conglomerate, Nantun Formation sandstone is mainly composed of lithic arkose and feldspathic lithic sandstone; Tongbomiao formation and Nantun Formation sandstone in Beier depression are mainly composed of lithic sandstone and feldspathic lithic sandstone, and feldspathic sandstone and lithic feldspathic sandstone appear in some areas of the second member of the south.

According to 181 rock and mineral identification data of Tongbomiao formation and Nantun Formation reservoir collected and self identified, statistical results are obtained.

The results show that the quartz content of sandstone in Tongbomiao formation is mainly $30-43 \%$, with an average of $37.78 \%$; feldspar content is $26-50 \%$, with an average of $36.89 \%$; volcanic rock debris is the main debris, with an average content of about $7.94 \%$; mica

\footnotetext{
* Corresponding author: dqzhouyue@petrochina.com.cn
} 
content is relatively high in three small layers, with an average of about $7.33 \%$; cement content is generally low, with a maximum of $36.5 \%$, with an average of $12.78 \%$. Nanyi member is the main sand body of Nantun Formation, mainly composed of lithic arkose and feldspathic lithic sandstone, with quartz content of 20$65 \%$, average value of $44.63 \%$; feldspar content of 13 $50 \%$, average value of $28.71 \%$; magmatic lithic debris with high content of $5-27 \%$, average value of $13.97 \%$; total lithic debris of $10-40 \%$, average value of $22.49 \%$; mica content of $4.2 \%$ and cement content of $14.79 \%$. The proportion of sandstone in the second member of the south part of the reservoir is small, mainly feldspathic lithic sandstone and a small amount of lithic sandstone. The average amount of lithic sandstone is about $26.28 \%$, and the main content is between $15 \%$ and $40 \%$. Among them, the content of metamorphic debris is higher than that of Tongbomiao formation and the first member of the south, with an average of $14.87 \%$; the content of quartz is between $20-71 \%$, with an average of $52.22 \%$; the content of feldspar is mainly $8-40 \%$, with an average of $18.22 \%$; the content of cement is higher, with a maximum of $47 \%$, with an average of $17.36 \%$.

The reservoir cement types of Nantun Formation in Wuerxun depression are mainly calcite, chlorite, kaolinite, illite, siliceous, feldspar, etc. the distribution characteristics and content of different types of cement in sandstone are quite different. Calcite cement is mainly pore cementation, and its content changes greatly. Tongbomiao formation is the highest, with an average of about $10.14 \%$. It is speculated that the sandstones of Tongbomiao formation are adjacent to the lacustrine mudstones of the first member of the south to obtain a large amount of calcium during the compaction process. The content of siliceous (mainly quartz edge) is the highest in the second member of the south, with an average of about $0.72 \%$. Authigenic clay minerals are the most common in the reservoir, among which chlorite and kaolinite are the main minerals with average contents of $6.88 \%$ and $2.78 \%$. Among them, chlorite content is relatively high, up to $10 \%$, average about $3.11 \%$ Kaolinite is relatively high in Tongbomiao formation, with an average of about $1.17 \%$, but the highest content occurs in the second member of the south, which is about $4.5 \%$.

In addition, the content of argillaceous (intergranular matrix and synsedimentary clay mineral) is not evenly distributed in the three reservoirs, showing the characteristics of high in the upper, low in the middle. The highest content is $10 \%$ in the first member of the south, and the average content of the second member is $4.5 \%$, which is lower than $6.7 \%$ and $5.8 \%$ of the first member of the South and the second member of the south.

\section{Reservoir space characteristics}

The rocks of Nantun Formation are compact as a whole, with poor connectivity of pores (Fig. 1). Primary pores and secondary pores coexist. The primary pores are mainly residual primary intergranular pores, which are mainly developed in the reservoirs with high content of quartz and feldspar in sandstones with chlorite film and microcrystalline quartz film. There are three main types: (1) clastic particles are chlorite, illite and Iraq/slip layer of clay film after cementation residual original intergranular pore, triangular, square and rectangular form, general large pore, between $0.01 \sim 0.5 \mathrm{~mm}$ in diameter,throughout noise and low content of plastic particles, separation of fine grained sandstone in moderate to good, (2) quartz overgrowth, cementation of authigenic quartz crystallite residual original intergranular pore content is less, after the quartz crystallite normally with membrane covered on the edge of the clastic particles, occupy the primary intergranular pore is small; (3) original intergranular pore after filling with heteroradical and early microcrystalline calcite cement, with irregular shape and relatively small pore diameter. The pore edge is straight, the inside is clean, the radius is large, common oil and gas filling.

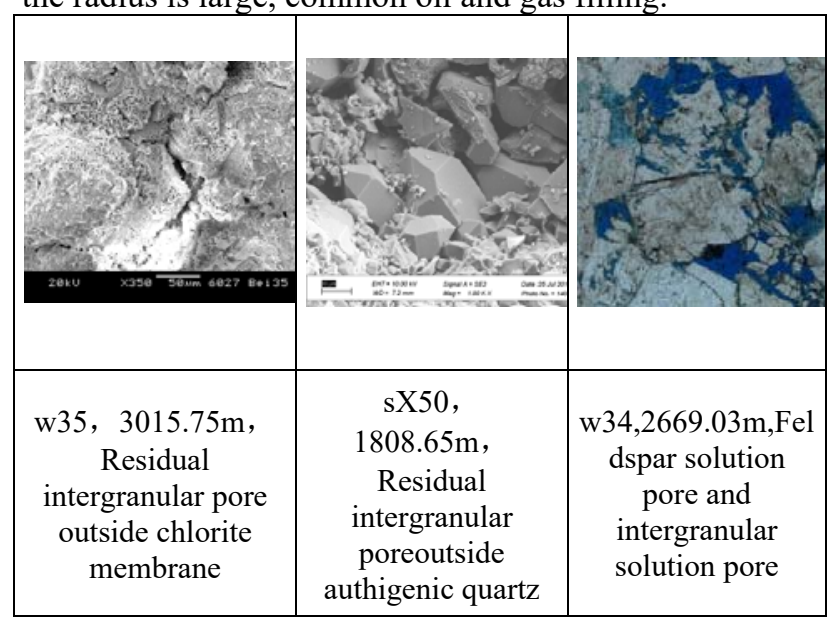

(a)

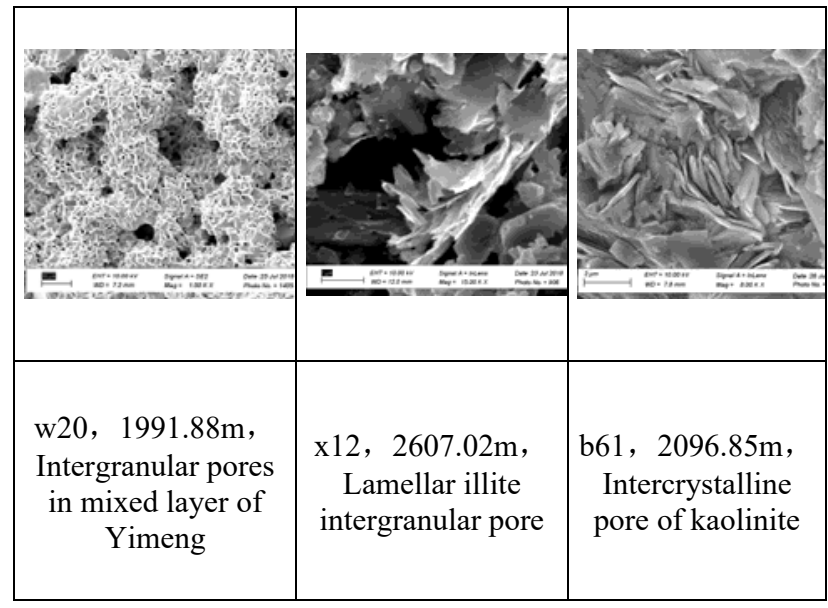

(b)

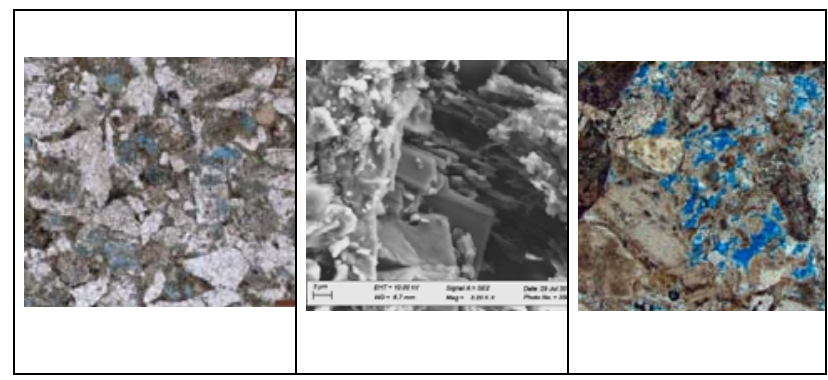




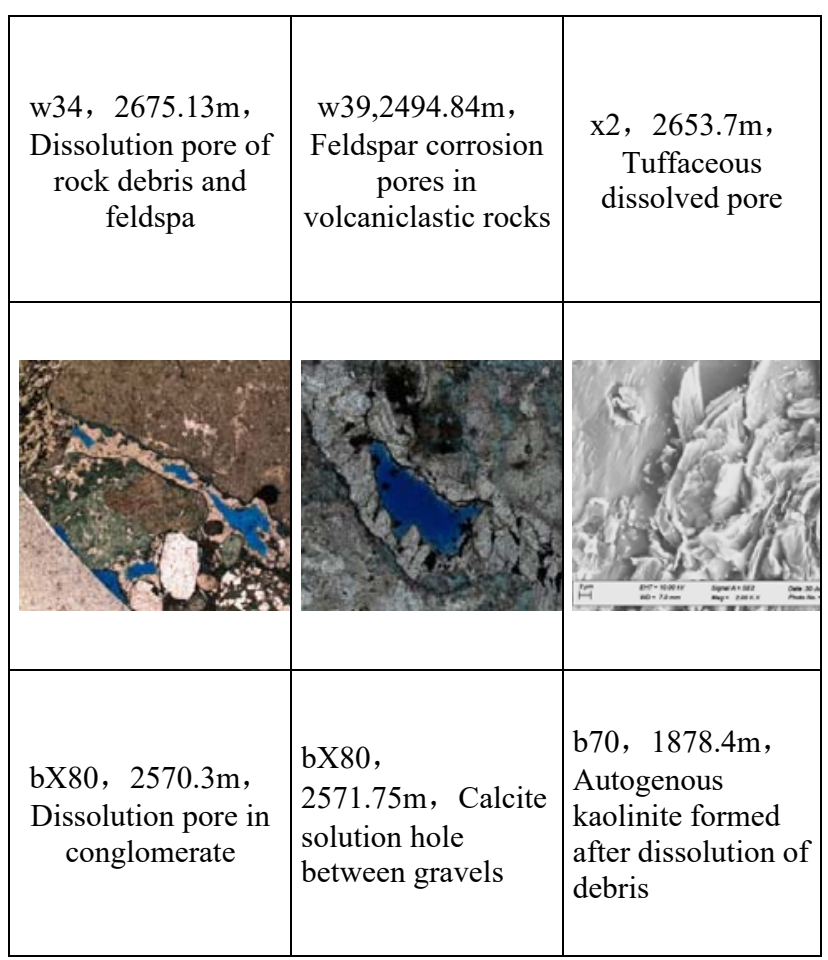

(c)

Fig. 1 Spatial characteristics of tight sandstone reservoir

Secondary pore is the main reservoir space of Nantun Formation, including dissolution intergranular pore, dissolution intergranular pore, interstitial matter dissolution pore, intergranular micro pore and micro fracture of authigenic minerals, among which intergranular dissolution pore is the most developed and super large dissolution intergranular pore is the main one.

The secondary pores are mainly intergranular, intragranular and marginal dissolution pores of feldspar and debris, dissolution pores of a small amount of carbonate cement and intergranular pores of clay minerals. Among them, intergranular dissolved pore is one of the most important pore types, which is generally formed by expanding dissolution along the particle edge or interstitial material on the basis of remaining primary pores. The dissolved components are mainly feldspar, calcite and cuttings, with irregular shape, uneven pore size and distribution, and poor connectivity. More often seen in feldspar, the distribution is very uneven, in the strong dissolution of the region, the surface of quartz particles also dissolved and formed a small secondary dissolution hole, after the dissolution of the quartz surface is uneven, the edge is irregular or bay shape; (3) interstitial pores in interstitial materials. Interstitial materials filled between particles are another soluble component of sandstone. Due to the low content of heterobaric groups in the study area, the content of such pores is relatively low. (4) authigenic mineral intercrystalline micropores mainly include kaolinite, illite, chlorite, eimon mixed layer, green mantle mixed layer and other intercrystalline pores. The number of intercrystalline pores is large, but the radius is small. They are mainly nanoscale pores with poor connectivity. (5) micro-fractures are only developed in individual segments of individual Wells, up to $1-2 \%$. Some of the micro-fractures have been filled, and the unfilled microfractures mainly play the role of connecting pores.

The secondary pore should refer to the new pore formed in the process of diagenesis. In the quantitative identification of the reservoir space type, the original intergranular pore and the new pore formed by the dissolution of the surrounding particles should be divided into primary pore and secondary pore. According to this principle, the content of primary and secondary porosity in 76 casting thin sections of 13 wells in the tight sandstone reservoir of Nantun Formation is calculated quantitatively. The results show that the relative content of primary pores is less than $50 \%$, only a few are more than $50 \%$, while the relative content of secondary pores is more than $50 \%$, some are more than $80 \%$. Therefore, the reservoir space in the study area is dominated by secondary pores.

\section{Conclusion}

The rock types of the target layer in the study area are mainly lithic sandstone and feldspathic lithic sandstone. Among them, Tongbomiao formation in Wuerxun depression is dominated by conglomerate, while sandstone in Nantun Formation is mainly lithic arkose and feldspathic lithic sandstone; sandstone in Tongbomiao formation and Nantun Formation in Beier depression is dominated by lithic sandstone and feldspathic lithic sandstone.

The rocks of Nantun Formation are compact as a whole, with poor connectivity of pores and coexistence of primary and secondary pores. The primary pores are mainly residual primary intergranular pores, mainly of three types.

Secondary pore is the main reservoir space of Nantun Formation, including dissolution intergranular pore, dissolution intergranular pore, interstitial matter dissolution pore, intergranular micro pore and micro fracture of authigenic minerals, among which intergranular dissolution pore is the most developed and super large dissolution intergranular pore is the main one.

\section{References}

1. Tang haifa, Pengshimi, Zhao yanchao 2006 Micro pore structure characteristics and classification evaluation of HE $2+3$ tight sandstone reservoir in Daniudi gas field (Chinese: Journal of Mineral rock) (03): pp109 115

2. Li pan 2019 Characterization of micro pore structure and production characteristics of low permeability sandstone reservoir (D)

3. Shao xinhe, Pang xiongqi, Hu tao 2019 Pore micro characteristics of Sha3 shale reservoir in Dongpu depression of Bohai Bay Basin and its significance for oil and gas retention (Chinese:Journal of Petroleum and natural gas geology)40 (01): pp 71 $\sim 81$

4. Yao jingli, Liu xiaopeng, Zhao huitao 2019 Reservoir characteristics of tight sandstone gas 
reservoir in He8 member of Ordos Basin and its integrated geological engineering countermeasures (Chinese: Journal of PetroChina exploration) 24 (2): pp $186 \sim 195$

5. Chen yiming, Wei xiuli, Xu huan 2012 Inspiration from the study of pore types of shale gas reservoirs in North America (Chinese: Journal of Complex reservoir) 5 (4): pp $19 \sim 22$ 